\title{
THE CORONAVIRUS CRISIS AND MIGRATION: INEQUALITIES, DISCRIMINATION, RESISTANCE
}

\author{
Francesco DELLA PUPPA', Fabio PEROCCO
}

Deriving from multiple ecological-social causes, the novel coronavirus and, subsequently, the COVID-19 pandemic, has affected all spheres of societies of the world. The COVID-19 pandemic has triggered and amplified an economic crisis that existed before the health crisis. The combination of the two crises into a double "ecologicalhealthcare" and "socio-economic" crisis has had multiple consequences for everyone on the economic, social, political, and cultural level; however, it has affected social classes, workers, genders, and territories in different ways, deepening social inequalities and worsening the social conditions of disadvantaged social groups: among the most affected social groups, we find migrants.

The purpose of this special issue is to critically analyze the relationship between the coronavirus crisis and migration, with particular attention to the condition of migrants in the global health crisis, new inequalities, discrimination, and their forms of resistance. Since international migration and the pandemic are two global phenomena, this special issue could only have a global look and approach at their intertwining. The articles consider, on the one hand, several national contexts across the world and, on the other, analyze the different dimensions of the relationship between the coronavirus crisis and migration globally.

Pandemics and migration also have other aspects in common. As global social phenomena, they share the profound transformative dynamic that the two enact on societies. Just as migration constitutes an important factor of social transformation, both in the contexts of origin and in those of destination of migrants - and even in those contexts of transit -, to the point of being identified as a factor characterizing this phase of capitalism, the pandemic will leave nothing "as it was before" and will constitute a watershed moment in what has been called the "age of migration." Furthermore, again in their capacity as global social phenomena, pandemics and migration reveal the deepest contradictions and social issues of contemporary society, its political organization. Much has been written on the social transformations brought about by migration, as well as on the ability of migration - in the wake of Sayad's lesson - to reveal what one has an interest in ignoring. Still, little has been

PhD in social sciences, senior lecturer at Ca' Foscari University of Venice; francesco.dellapuppa@ unive.it, https://orcid.org/0000-0003-1437-4719.

\| PhD in sociology, associate professor at Ca' Foscari University of Venice; fabio.perocco@unive.it, https://orcid.org/0000-0003-0991-0046. 
said about the global change that the pandemic is bringing about, as well as about its social revealing and political unveiling action. Therefore, in the next paragraph, before presenting the structure of the monographic section of this issue, we will try to fill a tiny part of this gap.

\section{THE CORONAVIRUS FACTOR}

If the novel coronavirus is a symptom of the current state of the environment and a sign of the progressive disease affecting the biosphere, the coronavirus crisis is a litmus test and a mirror exposing the structural problems of contemporary societies, highlighting the major crisis of our times. For instance, in the last decades, the national health systems of several countries have undergone a progressive deterioration or have been the object of strong attacks in the wake of neoliberal policies that have imposed a profound transformation under the banner of privatization/ semi-privatization, individualization, and corporatization. In the so-called "first pandemic wave," several health systems were overwhelmed by the pandemic due to the surprise effect, but also as a result of decades of state disengagement in public health, budget cuts, staff reduction, abandonment of territorial medicine, the concentration of medicine in large hospitals. The so-called second pandemic wave, which occurred in the fall of 2020, confirmed that the problems in national health systems were and, obviously, still are structural and could not be attributed to the surprise effect alone.

The coronavirus crisis has also been a formidable social accelerator, a potent factor in accelerating social trends that existed before the pandemic. It has expanded, generalized, and structured several social processes that predate the pandemic, entrenching them in the social structures and daily life of many countries. In addition to the "year of the global pandemic" or the "year of fear," 2020 should also be titled the "year of the great acceleration."

Among the many examples, suffice it to mention home food deliveries through apps and digital platforms, distance learning, smart working, the increased militarization of society and control over daily lives. All these phenomena predate - by far - the coronavirus crisis, yet it gave them new momentum, making a real leap in quantity that has sometimes turned into a leap in quality.

In particular, the coronavirus crisis has been an acceleration of social phenomena of a neo-liberal nature, for example, the individualization of education, which through the massive use of information technology has given a strong impetus for distance learning; or the social atomization magnified by the enormous growth of the web and digital labor. Above all, we should mention the sharpening of social inequalities and social polarization, the structural casualization of work, the increase in the number of the working poor, all phenomena that preceded the pandemic crisis but were extended and aggravated by it. 
Moreover, as already mentioned, the coronavirus crisis provided the capital with an opportunity to expand further, to penetrate even more deeply into all the spheres of social and natural life, to reorganize and, at the same time, subject society to the laws of capital even more stringently. It has been an occasion to expand its field of action and control even further and expand its boundaries.

As has already happened in the past, in times of crisis, the capital reorganizes itself. In doing so, it transforms the whole of society, depending on capital - starting from the labor market, the workplaces, and the economic processes.

Last but not least, the coronavirus crisis has also been a social detonator, a detonating factor. Both in its role as a litmus test and social accelerator, the coronavirus crisis has converged and entangled pre-existing social contradictions, exacerbating social hardships and inequalities, increasing social risks. In this regard, see the United States at the end of Trump's term. Several studies from a historical-comparative perspective (Snowden 2021), including some commissioned by the International Monetary Fund itself (Barret, Chen 2021; Sedik, Xu 2020), warn about the social conflicts and revolts that are emerging on the horizon, albeit with different intensities in different global contexts, and which, in the history of capitalism, have followed the inequalities exacerbated by the pandemic crises.

\section{MIGRANTS INTO THE STORM OF PANDEMIC}

If the coronavirus crisis amplified the social problems and inequalities that already existed, it has had differentiated effects hitting harder the working class, women, young and older people, minorities. At the same time, it has transformed inequalities, changing old ones, generating new ones, intertwining the old and the new.

An example of these processes, particularly the differentiated impact of the crisis, may be observed in migration. Immigrant workers, asylum seekers and refugees, and migrants experienced conditions and problems similar to those of the native population, yet often more severe. As the different papers will show, for many reasons, they have been particularly vulnerable to the pandemic and its economic and social effects. It affects them all over the world in a particularly hard way. They are doubly affected as migrants (the object of a real war on migration for years) and workers (the long-time target of an attack on labor). They often carry out the jobs considered essential for our everyday life: nurses, basic social and health workers, care workers, porters, logistics workers, home delivery carriers, food sector workers, etc. That is, humble, poorly paid, precarious laborers, often working without contracts and protections, highly exposed to the risk of contagion. Yet, despite their essential role in production processes, during the pandemic, they have often undergone an invisibilization process, they have been made invisible; yet, they were talked about when propaganda used them as a scapegoat, pointing at them as contaminated, infected with the virus, a threat to national health safety. 
Restricted in their mobility and stranded in countries of departure or transit, huddled in reception centers in precarious conditions and hampered in admission procedures and applications for asylum or international protection, forced to work despite health risks and made invisible to the public discourse, forgotten by public policies and discriminated against in their access to prevention or treatment, impoverished and more exploited in the labor market, accused of carrying the virus or being immune from it, segregated in the homes of the dependent elderly they assist, they are one of the most vulnerable groups at risk of suffering the heaviest consequences of this double crisis. The consequences are detectable in the process of their further impoverishment, with direct transnational and global implications on families left behind in the countries of origin. The first estimates of the World Bank for 2020 forecast a decline of about $20 \%$ of remittances: in absolute values, from 554 billion US dollars to 445 billion US dollars.' Furthermore, it is possible that, shortly, when humanity will have learned how to live with the pandemic and societies will be reshaped by its social-economic effects, the "virus issue" will be used instrumentally and ideologically in politics and rhetoric against migrants. That is, punishing legislation and propaganda against migrants - widely spread in Europe, the United States, and the world, but temporarily supplanted in the media by the theme of the pandemic - could become even harsher in affecting migrants, making entry and regular residence more difficult, discriminating them in the labor market and several areas of social life.

\section{THE STRUCTURE OF THE THEMATIC SECTION}

The thematic section is inaugurated by the article of Fabio Perocco, which provides a global framework on the origins and consequences of the coronavirus crisis, focusing on the effects of the syndemic on racial health inequalities and migrants, within which the other articles, the result of empirical cases, find their place.

Subsequently, Arun Kumar Acharya and Sanjib Pate present a comprehensive analysis on the perspective of socio-economic vulnerabilities faced by internal returnee labor migrants caused by the COVID-19 pandemic in India and the socioeconomic vulnerabilities they face back "home." Yasmin Saikia examines the plight of migrant Assamese Muslim garbage pickers in India during the COVID-19 lockdown and their tribulations in trying to return to Assam, which were all exacerbated by social, political, and religious prejudices. The article of Mohammad Riduan Parvez deals with returned migrants, in this case, in Bangladesh and, specifically, focusing on the discrimination and social harassment experienced by Bangladeshi returned migrants during the COVID-19 crisis. Nicola Costalunga brings us to Japan, describing

1 World Bank, https://www.worldbank.org/en/news/press-release/2020/04/22/worldbank-predicts-sharpest-decline-of-remittances-in-recent-history (15 Oct. 2020). 
how the emergency has been handled in the country, concerning foreign nationals and the country's border restrictions in the time of the pandemic.

Then, from Asia, we move to the Balkan area, in Europe, with two ethnographic contributions. In her article, Reena Kukreja examines undocumented Bangladeshi migrants in the Greek strawberry sector to highlight how racial capitalism heightens health vulnerabilities for racialized low-class migrant workers, exposing them to greater risk for coronavirus transmission. She analyzes how structural and systemic discriminations increase health precarity for undocumented agricultural workers. Then, Marina Cenedese and Ivana Spirovska compare the potential social exclusion and further marginalization of children of migrant origin and/or belonging to vulnerable social groups (Roma people) in two local contexts in North Macedonia and Italy.

Thus, we arrive in Italy, one of the first countries to be intensely affected by the pandemic and which, by virtue of its geographical position in the Mediterranean, is, in many cases, the first landing place and transit land for refugees and asylum seekers. Paola Bonizzoni and Senyo Dotsey demonstrate how differently-precarious legal conditions embedded in the Italian immigration system have interacted with the coronavirus crisis to produce specific outcomes of legal and social precarity. Davide Filippi and Luca Giliberti focus on the reception system for refugees and asylum seekers within the context of lockdown, during which some of the contradictions in the government's reception policy emerged more visibly. Stefania Spada analyzes the "quarantine ships," observed as a device for the externalization of borders; her contribution demonstrates how under the pandemic, Italy sharpened and intensified repressive logics and practices that disrespect human rights while introducing elements of novelty regarding the repercussions on the material conditions of existence of refugees and asylum seekers. The article by Giulia Sanò and Omid Firouzi Tabar, which compares two local contexts in the North and South of Italy, shows how within the Italian reception system, practices and procedures of "assistance," "care," and "control" have intertwined and alternated in the context of the pandemic, verifying whether there has been a definite shift toward the dimension of control.

This special issue covers a wide variety of geographical, social, and cultural contexts (from the Indian subcontinent to the Balkans, from Japan to Mediterranean Europe) and themes - returned migrants and social stigma; asylum seekers, the reception system and quarantine ships; labor exploitation and racial discrimination; school and social exclusion; national policies, precariousness and civic stratification. Understandably, for reasons of space and opportunities, many other areas of the world and research topics could not be explored in these pages. However, we aim to overcome this limitation with a second thematic section of this journal that, shortly, will present theoretical and empirical insights which, from the Americas to the Middle East, passing through Europe, Africa and Asia, will provide new angles of interpretation of the impact of the coronavirus crisis on migrants and migration and will provide an update on the evolution of this intertwining. 


\section{REFERENCES}

Barrett, Philip, Chen, Sophia (2021). Social Repercussions of Pandemics. IMF Working Paper, https://www.imf.org/en/Publications/WP/Issues/2021/01/29/SocialRepercussions-of-Pandemics-50041 (13 Apr. 2021).

Saadi Sedik, Tahsin, Xu, Rui (2020). A Vicious Cycle: How Pandemics Lead to Economic Despair and Social Unrest. IMF Working Paper, https://www.imf.org/en/Publications/ WP/Issues/2020/10/16/A-Vicious-Cycle-How-Pandemics\%20Lead-to-EconomicDespair-and-Social-Unrest-49806 (29 Mar. 2021).

Snowden, Frank (2021). Epidemics and Society. From the Black Death to the Present. Yale: Yale University Press. 